\title{
ANALISIS TINGKAT KESESUAIAN LOKASI BUDIDAYA RUMPUT LAUT DI PERAIRAN DESA KAMELANTA DAN PULAU PANJANG DENGAN MENGGUNAKAN SISTEM INFORMASI GEOGRAFIS
}

\section{(ANALYSIS SUITABILITY LOCATION FOR SEAWEED CULTURE AT KAMELANTA AND PULAU PANJANG BY USING GEOGRAPHIC INFORMATION SYSTEM)}

\author{
Arfan Afandi ${ }^{1}$, Fithriah Musadat ${ }^{2}$ \\ ${ }^{1}$ Program Studi Budidaya Perairan, Fakultas Perikanan dan Ilmu Kelautan, Universitas Dayanu \\ Ikhsanuddin, Baubau, Indonesia \\ ${ }^{2}$ Program Studi Teknik Informatika, Fakultas Teknik, Universitas Dayanu Ikhsanuddin, Baubau, \\ Indonesia \\ Korespondensi: arfanafandi05@gmail.com
}

\begin{abstract}
ABSTRAK
Penelitian ini bertujuan untuk menganalisis tingkat kesesuaian lokasi budidaya laut Desa Kamelanta dan Pulau Panjang Kabupaten Buton Sulawesi Tenggara bagi pengembangan budidaya rumput laut berdasarkan parameter kualitas perairan serta menentukan metode tanam yang dapat diterapkan di lokasi tersebut dengan menggunakan Sistem Informasi geografis (SIG). Parameter kualitas air yang digunakan adalah DO, Suhu, pH, Salinitas, Kecerahan, Kedalaman, Arus, serta kandungan Nitrat, Fosfat dan Clorofil-a. Hasil penelitian ini menunjukkan bahwa kualitas perairan Desa Kamelanta dan Pulau Panjang berada pada tingkatan "sesuai" dan "sangat sesuai" yang berkisar antara $80 \%$ - 89\%. Metode penanaman yang disarankan adalah metode longline sistem jalur.
\end{abstract}

Kata kunci : Lokasi Budidaya, Rumput laut, Sistem Informasi Geografis

\begin{abstract}
The goal of this study is to analize suitability location for seaweed culture at Kamelanta and Pulau Panjang, Buton Regency of Southeast Sulawesi based on water quality parameters and to determine the method of planting that can be applied in the location by using Geographic Information System (GIS). Water quality parameters used are DO, Temperature, $\mathrm{pH}$, Salinity, Brightness, Depth, Water Flow, and the contents of Nitrate, Phosphate, and Chlorophile-a. The result of this study indicate that the water quality of Kamelanta and Pulau Panjang is at "appropriate" and "very suitable" levels ranging from $80 \%$ to $89 \%$. The suggested planting method is long-line system path method.
\end{abstract}

Keywords: Location of Aquaculture, Seaweed, Geographic Information System

\footnotetext{
${ }^{1}$ Fakultas Perikanan dan Ilmu Kelautan, Universitas Teuku Umar Korespondensi : Program Studi Budidaya Perairan, Fakultas Perikanan dan Ilmu Kelautan, Universitas Dayanu Ikhsanuddin, Baubau Telp: +62 82322282926, email: arfanafandi05@gmail.com
} 


\section{PENDAHULUAN}

\subsection{Latar Belakang}

Rumput laut memiliki nilai ekonomis tinggi (high value commodity) yaitu sebagai penghasil karagenan yang bermanfaat untuk bahan baku untuk industri farmasi, kosmetik, makanan, dan lain-lain (Mubarak et. al., 1990; Nontji, 2002). Rumput laut jenis ini juga banyak dibudidayakan karena teknologi budidaya yang mudah, siklus produksi yang relatif singkat, dan biaya produksi relatif murah (Indriani dan Sumiarsih, 1996).

Kegiatan usaha budidaya rumput laut oleh masyarakat di Desa Kamelanta Kecamatan Kapontori Kabupaten Buton dilaksanakan sejak tahun 1990-an dengan berbekal pengalaman melihat dari tetangga maupun teman di Desa atau kelurahan lain tanpa penguasaan ilmu pengetahuan tentang budidaya yang baik. Penduduk Desa Kamelanta melakukan kegiatan budidaya rumput laut sebagai usaha sambilan utama selain sebagai nelayan. Penempatan rakit atau tali apung berada pada sekitar alur yang biasa dilalui oleh perahu-perahu nelayan sehingga perawatan dan pemeriksaan tanaman bisa dilakukan sesekali pada waktu senggang atau pada saat berangkat ataupun pulang melaut. Jenis rumput laut yang dibudidayakan adalah Eucheuma cottoni. Rumput laut jenis tersebut mengandung karaginan tinggi yang banyak mendukung industri makanan, farmasi, dan kosmetika (Meiyana, et al., 2001). Metode budidaya yang mereka terapkan adalah metode rakit Jalur dan metode long line, yaitu dengan mengikat rumput laut pada tali yang direntangkan.

Perencanaan pengembangan budidaya rumput laut di Indonesia, masih banyak mengalami hambatan. Salah satu kendalanya adalah lokasi perairan yang kurang cocok bagi kegiatan budidaya laut dan juga data parameter kualitas perairan yang tidak sesuai. (Ahmad et al., 1995 dalam Sudrajat et al., 1995). Guna keberhasilan budidaya rumput laut, maka penentuan lokasi yang sesuai dengan kondisi perairan, jenis komoditas yang unggul, metode budidaya yang tepat dan dekat dengan pusat konsumen perlu menjadi perhatian. Melalui perkembangan teknologi secara umum dewasa ini, Sistem Informasi Geografis (SIG) merupakan salah satu pilihan dalam penentuan lokasi ideal untuk pengembangan budidaya laut, khususnya rumput laut. SIG merupakan analisis secara spasial (keruangan) yang dapat memadukan beberapa data dan informasi tentang budidaya perikanan dalam bentuk lapisan (layer) yang nantinya dapat ditumpanglapiskan (overlay) pada data yang lain, sehingga menghasilkan suatu keluaran baru dalam bentuk peta tematik yang mempunyai tingkat efisiensi dan akurasi yang cukup tinggi.

\subsection{Tujuan Penelitian}

Penelitian ini bertujuan untuk menganalisis tingkat kesesuaian lokasi budidaya laut Desa Kamelanta dan Pulau Panjang Kabupaten Buton Sulawesi Tenggara bagi pengembangan budidaya rumput laut berdasarkan parameter kualitas perairan serta menentukan metode tanam yang dapat diterapkan di lokasi tersebut dengan menggunakan Sistem Informasi geografis (SIG).

\section{Metode Penelitian \\ 2.1 Lokasi Penelitian}

Penelitian dilaksanakan di dalam zona pemanfaatan budidaya laut Desa Kamelanta dan Pulau Panjang, Kecamatan Kapontori, Kabupaten Buton pada bulan Juli-November 2017. Metode yang digunakan dalam penelitian ini adalah metode survey dan penyajiannya memanfaatkan Sistem Informasi Geografis (SIG).

\subsection{Bahan dan Alat}

Bahan dan alat yang dipergunakan dalam penelitian ini adalah peta dasar, Echosounder, GPS, curren meter, Termometer, refraktometer, DO Meter, pinggan sechi, seperangkat komputer, dan alat tulis.

\subsection{Teknik Pengumpulan Data}

Untuk mengetahui kondisi lokasi penelitian maka dilakukan pengumpulan 
data yang terdiri dari data primer dan data sekunder. Pengumpulan data primer mengenai potensi sumberdaya lingkungan melalui pendugaan kualitas fisik, kimia, dan biologi perairan. Data mengenai kondisi sosial ekonomi dan budaya masyarakat dikumpulkan melalui studi dokumen, kuisioner, dan wawancara mendalam. Sedangkan untuk data sekunder dikumpulkan dari berbagai sumber yang memberikan informasi yang relevan terhadap penelitian seperti BAKOSURTANAL, BPS, BAPPEDA Kabupaten Buton, Dinas Perikanan dan Kelautan Kabupaten Buton Kecamatan, dan Desa.

\section{1) Potensi SumberDaya Lingkungan di Wilayah Pesisir Desa Kamelanta dan Pulau Panjang}

Data yang diambil untuk mengetahui potensi sumberdaya lingkungan meliputi pengukuran kondisi fisik, kimia, dan biologi perairan. Dalam hal ini, pengamatan kondisi fisik, kimia, dan biologi perairan dilakukan pada beberapa lokasi pengamatan. Pengukuran kualitas air dilakukan dengan pengambilan contoh air laut pada beberapa stasiun. Penentuan titik pengamatan menggunakan teknik Sistem random sampling, dengan jarak antara stasiun pengamatan menyesuaikan lokasi (Clark dan Hosking 1986). Setip lokasi pengamatan dipilih berdasarkan keterwakilannya dari segi ekosistem maupun pemanfaatan lingkungan perairan tersebut. Alat yang digunakan sebagai penanda di lapangan adalah Global Positioning System (GPS).

\section{2) Pendekatan Sosial Ekonomi dan \\ Budaya Masyarakat}

Penelitian ini memerlukan kajian yang mencakup aspek sosial budaya dan ekonomi masyarakat. Hal ini memiliki tujuan agar pengelolaan kawasan budidaya rumput laut yang dilakukan di Desa Kamelanta dan Pulau Panjang, Kabupaten Buton tidak semata-mata mengejar tingkat produktivitas, namun juga didasarkan pada pertimbangan kepentingan yang lebih luas yaitu terjaganya keselarasan kehidupan sosial ekonomi dan budaya masyarakat. Data-data dan informasi yang diperlukan adalah sebagai berikut: a) Data sosial dan budaya

(1) Data kependudukan

(2) Pola pemanfaatan sumberdaya

(3) Identifikasi adanya konflik pengelolaan dan pemanfaatan wilayah pesisir

(4) Kelembagaan sosial yang ada

(5) Kearifan lokal yang terkait dengan pemanfaatan sumberdaya pesisir

b) Data ekonomi

(1) Investasi Bisnis perikanan yang ada di Kabupaten Buton

(2) Produksi hasil perikanan

(3) Sistem dan rantai pemasaran produk perikanan

(4) Kelembagaan ekonomi yang mendukung pengembangan perikanan

Data-data tersebut berasal dari data primer yang diperoleh melalui investigasi langsung yaitu wawancara dengan masyarakat, maupun data sekunder yang berasal dari BPS, Bappeda, Dinas perikanan dan kelautan, Dinas Koperasi, LSM setempat dan dari berbagai sumber yang terkait.

\subsection{Analisis Data}

Bertujuan untuk menentukan kesesuaian lokasi budidaya rumput laut. Menurut Ismail, $d k k$ (2002), bahwa usaha kegiatan budidaya laut tidak dapat dilakukan disemua daerah pesisir karena membutuhkan beberapa persyaratan seperti persyaratan teknis, biologis, non teknis (sosial budaya dan ekonomi). Data yang berhubungan dengan persyaratan tersebut harus dapat dikelola dengan baik, sehingga dapat memberikan hasil analisis yang maksimal. Sejak banyaknya data dan informasi ini dalam bentuk spasial, Sistem Informasi Geografis (SIG) merupakan salah satu aplikasi yang sangat relevan dalam melakukan analisis ini. Data-data yang diperoleh untuk kemudian dikelompokkan berdasarkan tahapan analisis yaitu analisis spasial dengan SIG menggunakan perangkat Arcview 3.3.

Proses analisis awal dari pembuatan peta dasar digital di Desa Kamelanta dan Pulau Panjang, dimulai dari scan atau proyeksi peta rupa bumi ke dalam peta 
dasar. Peta dasar yang diperoleh bersumber dari hasil digitasi citra satelit. Kemudian dilakukan registrasi memindahkan titik koordinat peta rupa bumi ke dalam peta dasar.

Untuk mendapatkan kondisi perairan terkini dilakukan pemindahan peta citra ke dalam peta dasar. Setelah itu, dilakukan digitasi dan topologi yaitu mendigitasi dan mengidentifikasi peta dasar dengan informasi yang telah diambil dari peta rupa bumi dan citra. Selanjutnya diperoleh hasil peta dasar digital kawasan pesisir Kecamatan Kamelanta dan Pulau Panjang yang menjadi objek proses analisis spasial selanjutnya.

Data kualitas perairan yang dikumpulkan berasal dari titik-titik pengamatan yang penyebarannya mewakili lokasi penelitian. Untuk menganalisis secara spasial, terlebih dahulu dilakukan interpolasi, yang merupakan suatu metode pengolahan data titik menjadi area (polygon). Cara interpolasi titik menjadi area menggunakan metode Nearest Neighbor (Burrough \& McDonnell, 1998). Dari hasil interpolasi masing-masing parameter kualitas perairan yang diperoleh, disusun dalam bentuk peta tematik. Luasan perairan yang layak bagi kegiatan budidaya laut dihasilkan setelah seluruh data parameter utama pembobotan dalam bentuk peta tematik di overlay (tumpangsusunkan).

Penilaian secara kuantitatif terhadap tingkat kelayakan perairan dilakukan melalui pembobotandan skoring. Pembobotan pada setiap faktor pembatas di tentukan berdasarkan pada dominannya parameter tersebut terhadap peruntukan budidaya rumput laut. Untuk menentukan nilai akhir (skor) dari setiap faktor-faktor tersebut, maka dihitung perkalian bobot dengan skala penilaian, kemudian dihitung skor total semua faktor pembatas dari setiap kolom skala penilaian mulai dari Sangat sesuai (S1), sesuai (S2) dan tidak sesuai (S3).Adapun pengertian skala penilaian pada setiap kolom adalah sebagai berikut:

S1 (Sangat : lahan/perairan tidak mempunyai pembatas yang berat untuk suatu

Sesuai) penggunaan tertentu secara lestari

S2 (Sesuai) : Perairan mempunyai pembatas agak berat untuk suatu penggunaan tertentu secara lestari. Pembatas tersebut akan mengurangi produktivitas dan keuntungan yang diperoleh

S3 (tidak : Perairan mempunyai pembatas sangat berat/permanen, sehingga tidak sesuai) mungkin untuk digunakan terhadap penggunaan yang lestari.

Untuk mendapatkan selang nilai pada parameter tersebut dan batasannya dapat setiap kategori ditentukan parameter pembatas kegiatan budidaya. Parameterdilihat pada Tabel 1 .

Tabel 1. Kriteria Kesesuaian Lahan untuk Budidaya Rumput Laut

\begin{tabular}{|c|c|c|c|c|c|c|}
\hline \multirow{2}{*}{ No. } & Kriteria & \multirow{2}{*}{ Satuan } & \multirow{2}{*}{ Bobot } & \multicolumn{3}{|c|}{ Nilai } \\
\cline { 5 - 7 } & & & 3 & 2 & 1 \\
\hline 1 & $\mathrm{DO}$ & $\mathrm{mg} / \mathrm{l}$ & 2 & $>4$ & $2-4$ & $<2$ \\
\hline 2 & Suhu & ${ }^{\circ} \mathrm{C}$ & 1 & $27-30$ & $25-27 ; 30-32$ & $<25 ;>32$ \\
\hline 3 & $\begin{array}{c}\text { Derajat Keasaman } \\
(\mathrm{pH})\end{array}$ & & 1 & $7-8,5$ & $6,5-7 ; 8,5-9,5$ & $<6,5 ;>9,5$ \\
\hline 4 & Salinitas & $\mathrm{Ppt}$ & 1 & $29-33$ & $25-29 ; 33-37$ & $<25 ;>37$ \\
\hline 5 & Kecerahan & $\mathrm{M}$ & 2 & $>5$ & $3-5$ & $<3$ \\
\hline 6 & Kedalaman & $\mathrm{M}$ & 2 & $5-10$ & $1-4 ; 11-15$ & $<1 ;>15$ \\
\hline 7 & Arus & $\mathrm{Cm} / \mathrm{detik}$ & 2 & $20-40$ & $10-20 ; 40-50$ & $<10 ;>50$ \\
\hline 8 & Nitrat & $\mathrm{Mg} / \mathrm{l}$ & 2 & $0,1-0,7$ & $0,01-0,1$ & $<0,01$ \\
\hline 9 & Fosfat & $\mathrm{Mg} / \mathrm{l}$ & 1 & $0,1-0,2$ & $0,02-0,1$ & $<0,02$ \\
\hline 10 & Clorofil-a & & 1 & $3,5-10$ & $0,2-3,5$ & $<0,2$ \\
\hline
\end{tabular}


Sumber: SNI (2010); Modifikasi Radiarta et al (2010) dalam Hasnawi et al (2013); Kukuh Nirmala et al (2014); Nuning Mahmudah Noor (2015); Aslan (1998)

Untuk mendapatkan selang nilai pada setiap kategori ditentukan dari nilai persentase dari hasil perhitungan yang telah dilakukan. Kisaran persentase skala penilaian pada setiap kolom yaitu :

- Kategori Sangat sesuai (S1) : Y $\geq$ $85 \%$

- $\quad$ Kategori sesuai (S2) : Y $\leq 50-84 \%$

- $\quad$ Kategori tidak sesuai (S3) : Y $\leq 50 \%$

\section{Hasil dan Pembahasan Kondisi Umum}

Desa Kamelanta dibentuk berdasarkan Peraturan Daerah Kabupaten Buton Nomor 11 tahun 2005 yang secara administratif masuk dalam wilayah Kecamatan Kapontori Kabupaten Buton Sulawesi Tenggara dan memiliki luas 22 $\mathrm{km}^{2}$. Desa ini tepat berada di mulut Teluk Kapontori. Jarak ke ibu kota Kecamatan Kapontori sekitar $10 \mathrm{~km}$ atau $60 \mathrm{~km}$ dari ibu kota Kabupaten Buton. Pulau panjang yang juga menjadi tempat penelitian ini terletak tepat di depan pulau kamelanta. Secara administratif sebagian wilayahnya masuk dalam Desa Kamelanta, sebagian lagi di Desa Barangka. Kondisi topografi wilayah Desa ini berada di pesisir pantai dengan karakteristik tanah daratan berbatu dan tekstur pantainya landai dan terjal. Sebagian wilayah pesisir Desa Kamelanta bertipe pantai berlumpur yang diperuntukkan sebagai ekosistem mangrove, sebagian lainnya bertipe Bakau dan Lamun. Sedangkan di Pulau Panjang didominasi pantai berpasir, berbatu, dan sebagian terumbu karang.

Berdasarkan data BPS tahun 2016 Jumlah Kepala Keluarga Desa Kamelanta Menurut Lapangan Pekerjaan Utama Tahun 2015, Nelayan sebanyak 59 KK. Dari jumlah tersebut pembudidaya rumput laut sebanyak $45 \mathrm{KK}$ yang terdiri dari empat kelompok pembudidaya yaitu kelompok Laumbora dengan anggota 15 orang, kelompok Mulia Jaya dengan anggota 14 orang, Kelompok Tobea Damai dengan anggota 11 orang dan Kelompok Tobea Jaya dengan anggota 14 orang.

Sejak tahun 2007 budidaya rumput laut di Desa Kamelanta telah menjadi salah satu penggerak ekonomi masyarakat dimana produksi rata-rata mencapai 32 ton pertahun dan tahun 2015 mencapai 45,06 ton. Meningkatnya produksi ini seiring dengan kenaikan harga jual rumput laut dimana pada tahun 2007 harga rumput laut mencapai Rp. $20.000 / \mathrm{Kg}$ dan pada tahun 2010 - 2016 harga jual menurun pada kisaran Rp. 5.000 - 10.500/Kg. namun berdasarkan hasil survei pada beberapa pengepul baik di Desa Kamelanta maupun Pengepul Besar di Kota Baubau pada tahun 2017 harga rumput laut kembali naik mencapai Rp 19.000/Kg.

\subsection{Kondisi Kualitas Perairan}

Titik pengamatan kualitas perairan dibagi atas sepuluh stasiun, lima di perairan Desa Kamelanta dan lima lainnya mengitari Pulau Panjang. Sebaran titik pengamatan dapat dilihat pada Gambar 1.

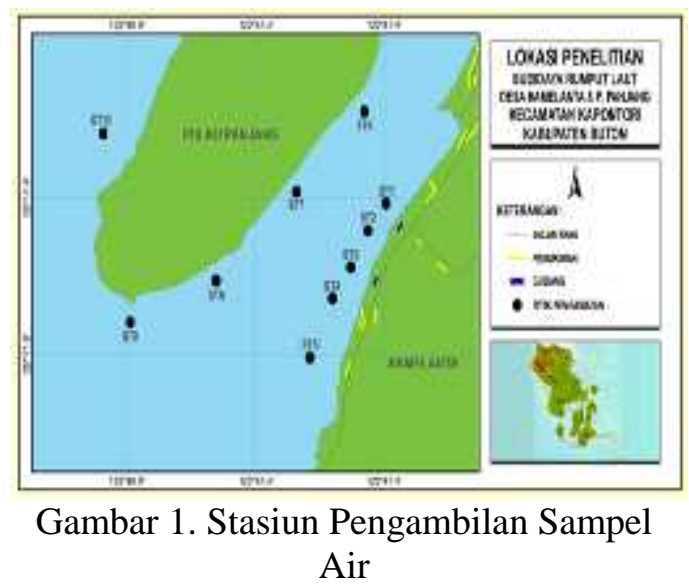

Selama delapan minggu dilakukan pengamatan kualitas perairan. Ringkasan data yang diperoleh dari hasil pengamatan tersebut dapat dilihat pada Tabel 2. 
Tabel 2. Rerata Parameter Kualitas Air pada Stasiun Pengamatan

\begin{tabular}{|c|c|c|c|c|c|c|c|c|c|c|}
\hline \multirow{2}{*}{$\begin{array}{l}\text { Parameter } \\
\text { kualitas air }\end{array}$} & \multicolumn{10}{|c|}{ Stasiun } \\
\hline & 1 & 2 & 3 & 4 & 5 & 6 & 7 & 8 & 9 & 10 \\
\hline $\mathrm{DO}(\mathrm{mg} / \mathrm{l})$ & 5,91 & 5,82 & 5,79 & 5,88 & 5,82 & 6,12 & 5,85 & 5,88 & 5,88 & 6,01 \\
\hline Suhu $\left({ }^{\circ} \mathrm{C}\right)$ & 28,75 & 28,79 & 28,75 & 28,69 & 28,55 & 28,79 & 28,71 & 28,65 & 28,56 & 28,58 \\
\hline $\mathrm{pH}$ & 7,18 & 7,08 & 7,18 & 7,19 & 7,33 & 7,26 & 6,99 & 7,13 & 7,11 & 7,46 \\
\hline Salinitas (ppt) & 30,63 & 30,88 & 30,25 & 31,13 & 30,88 & 30,88 & 31,13 & 31,13 & 31,38 & 30,88 \\
\hline Kecerahan (m) & 8,50 & 7,94 & 7,94 & 7,81 & 7,75 & 8,00 & 7,86 & 7,31 & 8,38 & 9,38 \\
\hline Kedalaman (m) & 10,00 & 10,00 & 11,00 & 10,00 & 10,00 & 11,00 & 11,00 & 10,00 & 10,00 & 10,00 \\
\hline Arus $(\mathrm{cm} /$ detik) & 10,95 & 8,16 & 11,60 & 10,07 & 6,99 & 13,35 & 13,69 & 13,68 & 15,66 & 17,67 \\
\hline Nitrat $(\mathrm{mg} / \mathrm{l})$ & 0,052 & 0,052 & 0,052 & 0,054 & 0,054 & 0,053 & 0,055 & 0,055 & 0,055 & 0,056 \\
\hline Fosfat (mg/l) & 0,017 & 0,018 & 0,013 & 0,009 & 0,007 & 0,020 & 0,014 & 0,019 & 0,007 & 0,020 \\
\hline Clorofil-a & 3,90 & 6,08 & 6,26 & 6,80 & 6,11 & 5,58 & 4,22 & 6,49 & 5,68 & 4,11 \\
\hline
\end{tabular}

Analisis Kesesuaian Lahan Berdasarkan Kualitas Perairan

Oksigen sangat dibutuhkan untuk tumbuh kembang rumput laut dalam mendukung proses metabolismenya. Oksigen merupakan dua macam gas yang memiliki arti penting dalam metabolisme. Oksigen dalam air berasal dari udara (melalui difusi) dan hasil sampingan fotosintesa tumbuhan akuatik (rumput laut). Kelarutan oksigen dalam air dipengaruhi oleh suhu air, ketinggian lokasi (latitude), salinitas, dan tekanan udara. Penambahan tekanan udara serta peningkatan suhu air dan salinitas, menyebabkan kelarutan oksigen rendah dan begitu pula sebaliknya (Wahyuningrum 2001). Dari hasil pengukuran oksigen terlarut (DO) di titik pengamatan sangat mendukung perkembangan rumput laut. Semuanya di atas angka $4 \mathrm{mg} / \mathrm{l}$ yang merupakan batas minimal untuk kriteria nilai DO yang sangat sesuai. Hasil pengamatan di setiap stasiun berkisar antara 5,79-6,12 mg/l.

Suhu suatu perairan dipengaruhi oleh radiasi matahari, posisi matahari, letak geografis, musim, kondisi awan, serta proses interaksi antara air dan udara, penguapan, dan hembusan angin (Dahuri et al. 2004 dalam Nirmala $d k k, 2014)$. Menurut Effendi (2003), perubahan suhu berpengaruh terhadap proses fisika, kimia, dan biologi badan air. Rata-rata nilai suhu di perairan Desa Kamelanta dan Pulau Panjang sangat sesuai yang berkisar antara $28,55-28,79{ }^{\circ} \mathrm{C}$. Suhu memiliki peranan penting dalam proses tumbuh rumput laut. Menurut Neish (2003) suhu air yang sesuai dengan kebutuhan hidup rumput laut Kappaphycus alvarezii adalah berkisar pada $28-32^{\circ} \mathrm{C}$. Kenaikan temperatur yang tinggi akan mengakibatkan thallus rumput laut menjadi pucat kekuningan dan tidak sehat, rumput laut dapat tumbuh dengan baik pada kisaran suhu $26-32{ }^{\circ} \mathrm{C}$ (DKP, 2006).

Nilai derajat keasaman hasil pengamatan menunjukkan bahwa perairan Desa Kamelanta dan Pulau Panjang masih berada pada kisaran yang sangat sesuai untuk budidaya rumput laut. Dari hasil pengukuran lapangan pada stasiun $1,2,3,4,5,6,8,9$ dan 10 nilai derajat keasaman $(\mathrm{pH})$ berkisar antara 7,08 - 7,46. Sedangkan pada stasiun 7 dengan nilai $\mathrm{pH}$ 6,99 masuk dalam kategori sesuai untuk pertumbuhan rumput laut. Nilai $\mathrm{pH}$ yang sesuai dengan kebutuhan rumput laut Eucheuma sp berkisar antara 7.2-8.2 (Iksan, 2005).

Hasil pengamatan salinitas menunjukkan bahwa perairan yang sangat sesuai untuk budidaya rumput laut, berkisar antara 29 - 33 ppt. Pengukuran salinitas 
perairan Desa Kamelanta dan Pulau Panjang masih berada pada kisaran yang sangat sesuai untuk pertumbuhan rumput laut, yaitu 30,63 - 31,38 ppt, menurut Anggadiredja et al, (2006) salinitas yang baik untuk pertumbuhan rumput laut berkisar 28-33 ppt.

Tingkat kecerahan yang tinggi diperlukan dalam budidaya rumput laut. Hal ini dimaksudkan agar cahaya matahari dapat masuk ke dalam air. Intensitas sinar yang diterima secara sempurna oleh thallus merupakan faktor utama dalam proses fotosintesis (DKP,2006). Faktor yang mempengaruhi kecerahan diantaranya kandungan lumpur, plankton, dan bahanbahan terlarut lainnya. Hasil pengamatan kecerahan berkisar antara 7,31 - 9,38 meter, yang berarti sangat sesuai untuk budidaya rumput laut karena nilainya lebih dari 5 meter.

Kedalaman perairan Desa Kamelanta dan Pulau Panjang di titik pengamatan berkisar 10 - 11 meter. Stasiun 1, 2, 4, 5, 8, 9, dan 10 menunjukkan angka yang sangat sesuai, sedangkan stasiun 3,6 , dan 7 menunjukkan bahwa pada titik tersebut sesuai sebagai lahan budidaya rumput laut. Kedalaman perairan yang baik untuk budidaya rumput laut berada pada kisaran 5 - 20 meter (DKP, 2006). Kedalaman perairan antara $5-20$ meter dimaksudkan agar rumput laut terhindar dari penumpukan partikel dasar perairan jika substrat dasarnya lumpur pada saat arus terlalu kencang terjadi. Kedalaman seperti ini juga terkait untuk kemudahan saat pemasangan jangkar pada metode tali rawai (Sulistijo, 2002).

Berdasarkan hasil pengukuran di stasiun pengamatan menunjukkan bahwa rata-rata arus perairan pada stasiun $1,3,4,6,7,8,9$ dan 10 berkisar antara 10,07 $17,67 \mathrm{~cm} /$ detik. Hal ini menunjukan bahwa arus perairan masih sesuai sedangkan hasil pengukuran terendah yang tidak sesuai untuk pembudidayaan rumput laut ada pada stasiun 2 dan 5, dengan kisaran antara 6,99 - 8, 16 Cm/detik . Menurut Wahyuningrum (2001), arus air yang baik akan membawa nutrisi bagi rumput laut untuk tumbuh serta untuk membersihkan kotoran maupun endapan yang menempel.
Selain itu, rumput laut juga akan tumbuh dengan baik karena ada kesempatan menyerap nutrisi (makanan) dari air dan proses fotosintesis tidak terganggu. Kecepatan arus yang terlalu kuat menyebabkan tanaman kesulitan menyerap nutrisi (makanan) yang berguna bagi pertumbuhan. secara umum arah arus di perairan Desa Kamelanta dan pulau panjang adalah Satu arah (unidirectional) yang bergerak dari Utara ke Selatan dan sebaliknya. Menurut Ariyati, $d k k$ (2007) Arah arus perlu diketahui untuk menentukan gambaran umum wadah budidaya sehingga sirkulasi air tetap lancar dan terkendali.

Nitrogen dan fosfat sangat penting bagi rumput laut dalam pengaturan metabolisme dan reproduksi. Pertumbuhan dapat tercapai dengan baik bila rumput laut tercukupi akan nitrogen dan fosfat. Pengambilan nitrogen dan fosfat oleh rumput laut bukan hanya fungsi dari konsentrasi nitrogen dan fosfat di lingkungan tetapi juga dengan konsentrasi nitrogen dan fosfat internal di dalam jaringan thallus rumput laut (Yu dan Yang, 2008). Kandungan nitrat di perairan Desa Kamelanta dan Pulau Panjang, dari hasil pengamatan rata-rata berkisar antara 0,052 - 0,056 mg/l, yang berarti masih sesuai untuk pembudidayaan rumput laut. Sedangkan kandungan fosfatnya untuk stasiun 6 dan 10 masih sesuai untuk pembudidayaan rumput laut, yakni 0,02 mg/l, sedangkan pada stasiun $1,2,3,4,5,7,8$ dan 9 tidak sesuai dengan rata-rata berkisar antara 0,007 - 0,019 mg/l. Lobban dan Horrison (1994), mengatakan bahwa pergerakan aliran air yang tinggi, rumput laut mudah stress karena terjadi perpindahan unsur hara cepat. Untuk mencukupi kebutuhannya nitrogen dan fosfat yang tersimpan di dalam jaringan dipergunakan terlebih dahulu untuk pertumbuhan (Risjani, 1999 dalam Djafar, 2011)

Dari hasil pengamatan tentang kandungan Clorofil-a, perairan Desa Kamelanta dan Pulau Panjang masuk dalam kategori sangat sesuai untuk pembudidayaan rumput laut, berkisar antara 3,9 - 6,8. Nilai Chlorofil-a yang baik 
tersebut menunjukkan bahwa di perairan tersebut tumbuh dengan baik fitoplanktonfitoplankton yang berkhlorofil. Hutabarat dan Evans (2000) menyatakan bahwa produktifitas perairan akan tinggi pada daerah perairan yang mengandung banyak fitoplankton dan kaya akan bahan organik

Secara simultan, berdasarkan hasil pengamatan dan analisis kualitas perairan di
Desa Kamelanta dan Pulau Panjang menunjukkan hasil yang sesuai bahkan sangat sesuai untuk dijadikan lahan pembudidayaan rumput laut. Proses perhitungannya dapat dilihat pada Tabel 3 . Tabel 3. Hasil Pembobotan Kualitas Air pada Stasiun Pengamatan

\begin{tabular}{|l|c|c|c|c|c|c|c|c|c|c|}
\hline \multicolumn{1}{|c|}{$\begin{array}{c}\text { Parameter } \\
\text { Kualitas Air }\end{array}$} & $\mathbf{1}$ & $\mathbf{2}$ & $\mathbf{3}$ & $\mathbf{4}$ & $\mathbf{5}$ & $\mathbf{6}$ & $\mathbf{7}$ & $\mathbf{8}$ & $\mathbf{9}$ & $\mathbf{1 0}$ \\
\hline DO & 6 & 6 & 6 & 6 & 6 & 6 & 6 & 6 & 6 & 6 \\
\hline Suhu & 3 & 3 & 3 & 3 & 3 & 3 & 3 & 3 & 3 & 3 \\
\hline pH & 3 & 3 & 3 & 3 & 3 & 3 & 2 & 3 & 3 & 3 \\
\hline Salinitas (ppt) & 3 & 3 & 3 & 3 & 3 & 3 & 3 & 3 & 3 & 3 \\
\hline Kecerahan (m) & 6 & 6 & 6 & 6 & 6 & 6 & 6 & 6 & 6 & 6 \\
\hline Kedalaman (m) & 6 & 6 & 4 & 6 & 6 & 4 & 4 & 6 & 6 & 6 \\
\hline Arus (cm/detik) & 4 & 2 & 4 & 4 & 2 & 4 & 4 & 4 & 4 & 4 \\
\hline Nitrat & 4 & 4 & 4 & 4 & 4 & 4 & 4 & 4 & 4 & 4 \\
\hline Fosfat & 1 & 1 & 1 & 1 & 1 & 2 & 1 & 1 & 1 & 2 \\
\hline Clorofil-a & 3 & 3 & 3 & 3 & 3 & 3 & 3 & 3 & 3 & 3 \\
\hline TOTAL BOBOT & 39 & 37 & 37 & 39 & 37 & 38 & 36 & 39 & 39 & 40 \\
\hline PERSENTASE & $87 \%$ & $82 \%$ & $82 \%$ & $87 \%$ & $82 \%$ & $84 \%$ & $80 \%$ & $87 \%$ & $87 \%$ & $89 \%$ \\
\hline KRITERIA & $\mathrm{S} 1$ & $\mathrm{~S} 2$ & $\mathrm{~S} 2$ & $\mathrm{~S} 1$ & $\mathrm{~S} 2$ & $\mathrm{~S} 2$ & $\mathrm{~S} 2$ & $\mathrm{~S} 1$ & $\mathrm{~S} 1$ & $\mathrm{~S} 1$ \\
\hline
\end{tabular}

Berdasarkan hasil pembobotan kualitas air pada stasiun pengamtan diatas maka di dapatkan Peta Tematik Lokasi Pembudidayaan Rumput Laut di desa Kamelanta dan Pulau Panjang Kecamatan Kapontori Kabupaten Buton sebagaimana pada gambar 2. berikut ini :

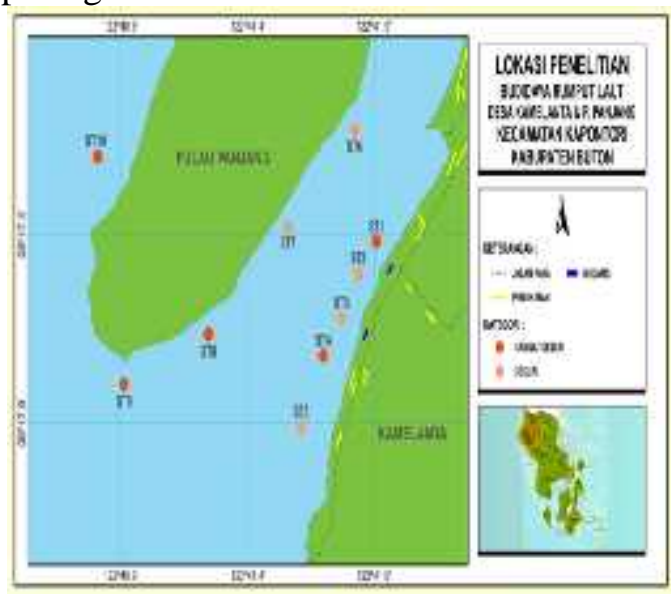

Gambar 2. Peta Tematik Lokasi Budidaya

Rumput laut

Sesuai dengan tingkat kedalaman perairan daerah pengamatan dan kondisi parameter kualitas air yang diperoleh terutama pergerakaan arah arus yang mengalir serta hasil wawancara dengan para pembudidaya rumput laut di Desa Kamelanta maka metode Budidaya yang sesuai dengan kondisi perairan Desa Kamelanta dan Pulau Panjang adalah Metode Long-line sistem Jalur.

Metode Budidaya Long-line Sistem Jalur ini merupakan metode apung budidaya rumput laut kombinasi antara metode long-line tali rambat dengan metode rakit dimana pada metode ini setiap jarak tertentu diberikan palang bambu untuk mempertahankan posisi tali ris sehingga tidak saling berkaitan. 


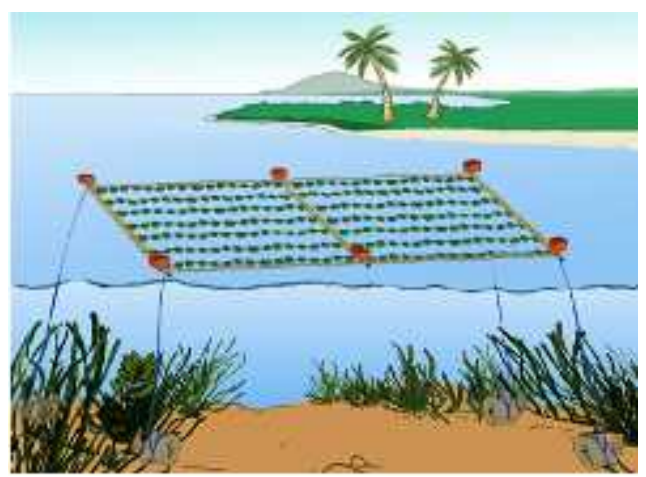

Gambar 3. Ilustrasi Metode Long-line Sistem Jalur

\section{Kesimpulan}

Berdasarkan hasil penelitian dapat disimpulkan Kualitas perairan Desa Kamelanta dan Pulau Panjang berada pada tingkatan "sesuai" dan "sangat sesuai" dengan rentang nilai $80 \%$ - $89 \%$. Metode budidaya rumput laut yang disarankan adalah metode long-line sistem Jalur.

\section{Daftar Pustaka}

Anggadiredja JA, Zatnika H, Purwoto dan Istini S. 2006. Rumput Laut, Pembudidayaan, Pengolahan dan Pemasaran Komoditas Perikanan Potensial. Penebar Swadaya. Jakarta. 147 hal.

Ariyati RW, Sya'rani L, dan Arini E. 2007. Analisis Kesesuaian Perairan Pulau Karimunjawa dan Pulau Kemujan Sebagai Lahan Budidaya Rumput Laut Menggunakan Sistem Informasi Geografis. Jurnal Pasir Laut. 3(1): 27-45 hal.

Aslan LM. 1998. Budidaya Rumput Laut. Penerbit Kanisius. Yogyakarta.

Burrough \& McDonnell. 1998. Principles of Geographical Information Sistem. New york: Oxford University Press

Clark WAV \& Hosking PL. 1986. Statistical Methodsfor Geographers. John Wiley \& Sons, Inc.

Departemen Kelautan dan Perikanan. 2006. Petunjuk Teknis Budidaya Rumput Laut Eucheuma spp. Jakarta.

Djafar F. 2011. Kajian Retensi Nitrogen Dan Fosfat Rumput Laut
(Kappaphycus alvarezii) Pada Berbagai Kecepatan Aliran Air. Tesis. Sekolah Pascasarjana Institut Pertanian Bogor.

Effendi H. 2003. Telaah kualitas air bagi pengelolaan sumber daya dan lingkungan perairan. Kanisius. Yogyakarta.

Iksan K. 2005. Kajian Pertumbuhan, Produksi Rumput Laut (Eucheuma cottoniii), dan Kandungan Karaginan pada berbagai Bobot Bibit dan Asal Thallus di Perairan Desa Guruaping Oba Maluku Utara. [tesis]. Bogor: Program Pascasarjana, Institut Pertanian Bogor.

Hasnawi, Makmur, Paena M, Dan Mustafa A. 2013. Analisis Kesesuaian Lahan Budidaya Rumput Laut ( Kappaphycus Alvarezii ) Di Kabupaten Parigi Moutong Provinsi Sulawesi Tengah. Jurnal Riset Akuakultur Vol. 8. Balai Penelitian Dan Pengembangan Budidaya Air Payau. Maros.

Indriani H dan Sumiarsih E. 1996. Budidaya, Pengelolaan dan Pemasaran Rumput Laut. Penebar Swadaya. Jakarta. 99 hal.

Lobban CS, Horrison PJ. 1994. Seaweed Ecology and Physiology. United States of America. Cambridge University Press.

Meiyana M, Evalawati, Arief P. 2001. Teknologi Budidaya Rumput Laut (Kappaphicus alvarezii). Biologi Rumput Laut. Balai Budidaya Laut Lampung. 3-8 hal

Mubarak H, Ilyas S, Ismail W, Wahyuni IS, Hartati ST, Pratiwi E, Jangkaru Z \& Arifudin R. 1990. Petunjuk Teknis Budidaya Rumput Laut. Pusat Penelitian Dan Pengembangan Pertanian. Departemen Pertanian. Jakarta. 93 hal.

Neish I. 2003. The ABC of Eucheuma Seaplant Production : Agronomy, Biology and Crop-handling of Betaphycus, Eucheuma and Kappaphycus the Gelatinae, Spinosum and Cottonii of Commerce. Monograph 1-0703, SuriaLink Seaplants. 
Nuning MN. 2015. Analisis Kesesuaian Perairan Ketapang Lampung Selatan sebagai Lahan Budidaya Rumput Laut Kappaphycus Alvarezii. Maspari Journal, 7(2): 91-100 hal.

Nirmala K, Ratnasari A dan Budiman S. 2014. Penentuan kesesuaian lokasi budidaya rumput laut di perairan Teluk Gerupuk - Nusa Tenggara Barat menggunakan penginderaan jauh dan SIG. Jurnal Akuakultur Indonesia 13 (1), 73-82 hal.

Nontji. 2002. Laut Nusantara. PT. Pradnya Paramita. Jakarta. 367 hal.

SNI [Standar Nasional Indonesia]. 2010. Produksi Rumput Laut Kotoni (Eucheuma cottonii). Bagian 1 : Metode Lepas Dasar. Badan Standarisasi Indonesia. Jakarta.
Sulistijo MS. 2002. Penelitian Budidaya Rumput Laut (Alga Makro/Seaweed) di Indonesia. Pusat Penelitian Oseanografi Lembaga Ilmu Pengetahuan Indonesia. Jakarta

Wahyuningrum PI. 2001. Studi evaluasi kesesuaian wilayah perairan teluk lampung untuk budidaya rumput laut Eucheuma dengan pemanfaatan penginderaan jauh dan system informasi geografi (SIG) [Skripsi]. Bogor: Institut Pertanian Bogor

Yu J dan Yu FY. 2008. Physiological and biochemical response of seaweed Gracilaria lemaneiformis to concentration changes of $\mathrm{N}$ and $\mathrm{P}$. Journal of Experimental Marine Biology and Ecology 367. 142-148 hal. 